\title{
Die verbruikersetiese gedrag van Suid-Afrikaanse bestuurders

\author{
Consumer ethics behaviour of South African managers
}

Christo BisschofF

NWU Besigheidskool

Noordwes-Universiteit

Potchefstroom

Suid-Afrika

E-pos: christo.bisschoff@nwu.ac.za

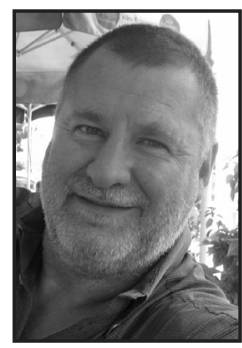

Christo Bisschoff

Christo Bisschoff het sy loopbaan as landbou-ekonoom begin waarna hy as dosent in Ondernemingsbestuur by die Universiteit van Pretoria aansluit. Hy studeer deeltyds en behaal die grade MCom (1990) en DCom (1992) aan die Universiteit van Suid-Afrika. Sy spesialiteitsvelde is Bemarkings- en Landboubestuur. Christo fokus later op handelsmerkstrategie, bestuursetiek en doen verder steeds navorsing oor sy gunstelingonderwerp, landboubestuur. Sy navorsing behels vergelykende studies wat hy saam met sy internasionale medewerker-netwerk doen en hy het reeds verskeie geakkrediteerde artikels publiseer en internasionale konferensies oor die wêreld heen toegespreek. Hy tree verder op as referent vir verskeie plaaslike en internasionale tydskrifte en was ook die voorsitter van die Internasionale Besigheidskonferensie. Hier tree hy steeds op as die redakteur van die konferensiebundel. Christo doseer Bemarkingsbestuur aan die Noordwes-Universiteit se NWUBesigheidskool op Potchefstroom.
Christo Bisschoff started his career as an agricultural economist, whereafter he joined the University of Pretoria as a lecturer in Business Management. He studied part-time at the University of South Africa and obtained the degrees of MCom (1990) and DCom (1992), with specialisation in Marketing and Agricultural Business Management. Christo focuses his research on brand loyalty, business ethics and still does research on his favourite topic, agricultural business management. He collaborates with his international network and also focuses on comparative research. He has published a wide array of accredited articles and has addressed audiences at international conferences, has acted as reviewer for a number of accredited journals. He resigned as the chairman of the International Business Conference, but still serves as editor in order to publish the conference proceedings. Christo lectures Marketing Management at the NorthWest University's Business School in Potchefstroom.

\begin{tabular}{|c|c|c|}
\hline $\begin{array}{l}\text { Datums: } \\
\text { Ontvang: 2021-06-23 }\end{array}$ & Goedgekeur: 2021-10-11 & Gepubliseer: Desember 2021 \\
\hline
\end{tabular}




\section{ABSTRACT}

\section{Consumer ethics behaviour of South African managers}

This study aimed to analyse the consumer ethics behaviour of South African managers when they make business decisions in their personal capacity. This means the decisions have a direct and personal impact on the manager; the manager suffers the consequences or gains benefits from their decisions and not the company they work for. The literature base explores rationalisation of unethical behaviour to sensitise the reader to defence mechanisms for unethical behaviour. The mechanism neutralisation and normalisation are used to explain unethical behaviour and why the boundaries are always pushed. The literature also seeks to identify demographic variables and their relationships to respondents as a guide to determine where potential relationships in this study could be identified. The population consists of graduate managers with at least three years of management experience. A snowball sample was used online to invite South African managers with three years managerial experience and a university degree to partake in the study; 102 completed the questionnaire. The data was subjected to testing sample adequacy using the Kaiser, Meyer and Olkin test (KMO=0.790), sphericity as per Bartlett's test was significant $(\chi 2(91)=396.550, p<0.05)$ and the reliability according to Cronbach alpha $(\alpha=0.853)$. The results show that both the ethical attitudes and ethical behaviour are well below the midpoint of 3.5; this signifies acceptable ethical attitudes and behaviours. However, closer scrutiny shows that in nine of the 14 scenarios, the managers behaviour is statistically significantly less ethical than their attitude profile. In one scenario (keeping the extra change), the unethical behaviour is also moderately practically significant $(d=0.58)$ as measured by Cohen's $d$-value. No significant correlations were identified between the demographic variables and the scenarios. Exploratory factor analysis (explaining a cumulative variance of $60.52 \%$ ) extracted three factors. These are misleading behaviour (37.04\% variance), untruthful behaviour (13.71\% variance), and price benefit $(9.77 \%$ variance). All three factors have excellent reliability coefficients. The results show that although the managers have ethical attitudes and behaviours well within the ethical boundaries, their behaviour is less ethical than their attitudes. Here, three scenarios are specifically worrisome because all three are regarded (attitude) as acceptable behaviour (when they are not), and the managers indicated that they also act unethically upon these scenarios. These scenarios are to keep quiet if a product is incorrectly priced, test products in shop but order from elsewhere, and misuse limited offer specials. The study also shows that although the managers know better, overall, they are pushing the boundaries and behave less ethically; albeit still within the general ethical sphere, it is less ethical than their attitudes indicate. The ethical basis is good. It is promising that managers know what the right thing to do is, and behave accordingly, especially for a country like South Africa where corruption, state capture and personal gain in business decisions are rife. The measurement of attitudes provides a barometer of the business ethical atmosphere of South African managers. Attitudes are strong behavioural drivers. This means that behaviour in consumer ethics can be positively influenced if attitudes are showing a positive inclination towards ethical consumer decisions.

\section{OPSOMMING}

Dié studie ondersoek die gedrag in verbruikersetiek wat onder Suid-Afrikaanse besigheidsbestuurders heers. Die studie ondersoek die etiese houdings, en vergelyk dit daarna met die spektrum van etiese gedrag wat die groep bestuurders openbaar. Die populasie van die studie bestaan uit bestuurders wat oor ten minste drie jaar bestuurservaring beskik en gegradueerd is. 'n Sneeubal-steekproef het 102 bruikbare vraelyste gerealiseer wat ontleed is nadat dit 
statisties voldoende bevind is deur Kaiser, Meyer en Olkin se toets om te bepaal of die steekproef voldoende is al dan nie. Nege van die 14 twyfelagtige gedragscenario's verskil statisties betekenisvol van die etiese houdings wat die bestuurders handhaaf, en dui daarop dat die bestuurders nie altyd so eties optree soos wat hul houdings voorhou nie. Die algemene tellings is egter bevredigend en beide die etiese houdings (2.47) en etiese gedrag (2.94) is onder die middelpunt waarde van 3.5. Voorts word die onderliggende faktore ook bepaal van die etiese gedrag deur 'n ondersoekende faktorontleding in te span. Drie faktore is geïdentifiseer, naamlik misleidende gedrag (37.04\%), oneerlike optrede (13.71\%), en prysvoordeel (9.77\%). Die studie bevind verder dat daar nie betekenisvolle verwantskappe tussen die bestuurders se etiese gedrag en hul demografiese veranderlikes is nie. Die resultate is bemoedigend, selfs al tree die bestuurders meer oneties op as wat hul houdings voorstel, omdat die gedrag oor die algemeen as eties beskou word, en slegs drie uit die 14 scenario's 'n telling bo die 3.5 middelpunt het. Dit toon dat hulle oor die algemeen in hul persoonlike besluitneming etiese besluite maak. Daar is egter steeds ruimte vir verbetering.

KEYWORDS: $\quad$ ethics, behaviour, managers, South Africa, perceptions, profile, attitudes, consumer, decision-making

TREFWOORDE: etiek, gedrag, bestuurders, Suid-Afrika, persepsies, profiel, houdings, verbruikers, besluitneming

\section{Inleiding}

Etiese houdings word wêreldwyd nagevors, ook in Suid-Afrika. Min studies doen egter direkte vergelykings tussen 'n groep respondente se etiese houding en hulle gedrag. Die vraag is dus hoe hierdie etiese houdings manifesteer wanneer dit by etiese gedrag kom, en ook hoe hierdie gedrag verskil wanneer besluite gemaak word in besigheidsverband teenoor besluite wat gemaak word in 'n persoonlike hoedanigheid. Logiese redenasie dikteer dat 'n teikengroep (in hierdie studie gegradueerde besigheidsbestuurders) meer eties behoort op te tree indien hulle bevredigende etiese houdings handhaaf. Tog is dit nie altyd die geval nie. Nel het reeds in 1989 bevind, soos ook later bevestig deur Bisschoff en Fullerton (2014:19), dat etiese gedrag soms nie strook met goeie etiese houdings nie. Verskeie studies wat in 12 lande versprei was oor ses kontinente, soos opgesom deur Fullerton en Bisschoff (2013), het getoon dat daar etiese verskille voorkom tussen persoonlike en besigheidsbesluite. Beide die populêre pers en geakkrediteerde navorsingsjoernale publiseer gereeld hoe verbruikers en besighede oneties, en selfs onwettig optree, in hul besigheidsaktiwiteite. Etiese gedrag verskil dus nie net waar onetiese gedrag voorkom onder besluitnemers wat wel goeie etiese houdings handhaaf nie, maar dit verskil ook wanneer die besluit 'n persoonlik impak het. Hierdie studie ondersoek dus die bestuurders se etiese gedrag ten opsigte van die persoonlike besluite wat hulle neem.

\section{Literatuurstudie}

Hierdie literatuurstudie ondersoek twee aspekte van etiese verbruikersgedrag. Eerstens word die konsepte van neutralisasie en normalisasie in die verbruikersetiek toegelig. Verbruikers gebruik die tegnieke om hul onetiese gedrag te rasionaliseer, en dit is daarom belangrik om kennis te neem daarvan in studies wat etiese gedrag ondersoek. Tweedens word die literatuur ondersoek om verbandskappe tussen demografiese veranderlikes en etiese gedrag te identifiseer.

Tydskrif vir Geesteswetenskappe, Jaargang 61 No. 4-2: Desember 2021 doi.10.17159/2224-7912/2021/v61n4-2a9 


\section{Neutralisasie en normalisasie in verbruikersetiek}

Die term neutralisasie is reeds in 1957 deur die kriminoloë Sykes en Matza (1957) geïdentifiseer en word beskryf as die wyse waarop verbruikers hul nie-normatiewe gedrag rasionaliseer. Verbruikers is minder krities teenoor eties twyfelagtige gedrag indien daar nie 'n duidelik geïdentifiseerde slagoffer is nie (Kvalnes, 2019:119). (Hierdie rasionaal is oorspronklik deur Grove, Vitell en Strutton (1989) gebruik om onetiese verbruikersgedrag te evalueer en te ondersoek.) Onetiese verbruikers rasionaliseer hul onetiese gedrag deur een of meer van die volgende tegnieke in te span:

\section{- Ontken die bestaan van 'n slagoffer}

Onetiese gedrag word as minder ernstig of selfs aanvaarbaar geag indien daar geen slagoffer is wat skade ly as gevolg van die gedrag nie (Kaptein \& Van Helvoort, 2019:1261). In dié verband toon Fullerton, Kerch en Dodge (1996:807) egter in die ontwikkeling van die Verbruiker-etiese Indeks dat twee onderliggende veranderlikes hier 'n rol speel, naamlik gedrag wat tot direkte ekonomiese gevolge lei (byvoorbeeld deur te veel kleingeld te hou - sien Scenario A1 in die vraelys), en verskuilde ekonomiese konsekwensies (byvoorbeeld om 'n pas gekoopte produk terug te gee by ' $n$ ander winkel as waar dit aangekoop is). (Beide hierdie konsepte word getoets deur die scenario's in die vraelys - sien Bylaag 1: Scenario's A1 en A9.) Onetiese verbruikersgedrag word geneutraliseer deur die feite met betrekking tot die onetiese gedrag te verdraai, as die halwe waarheid voor te hou, of om die geval as onwaar af te maak (Kaptein \& Van Helvoort, 2019:1268).

- Ontkenning van verantwoordelikheid

Die onetiese verbruiker neutraliseer enige verantwoordelikheid van sy of haar gedrag deur bloot te ontken dat die onetiese gedrag binne sy of haar verantwoordelikheidsraamwerk val (Smith et al., 2007:8). In hierdie geval word veral drie uitweë gebruik, naamlik dat 1) die onetiese aksie buite die verbruiker se rol val, 2) die aksie die gevolg was van beperkte opsies tydens die omstandighede waarbinne dit gepleeg is, of dat 3 ) die druk en versoekings net te groot was om te weerstaan (Kaptein \& Van Helvoort, 2019:1268). Hierdie is tipiese gedrag wat 'n eksterne lokus van kontrole by die onetiese verbruiker weerspieël (Ogoun \& Odogwu, 2020:6).

\section{- $\quad$ Ontkenning van skade}

In hierdie neutralisasietegniek poog die verbruiker om te ontken dat die onetiese aksie enige skade veroorsaak het (Kvalnes \& Nordal, 2018:5). So sal 'n motoreienaar van 'n motor met hoë brandstofverbruik byvoorbeeld argumenteer dat die besoedeling van sy voertuig se uitlaatgasse nie enige ander persoon direk enige skade berokken nie. Trouens, indien hy of sy eerder werk toe stap of dan 'n meer ekonomiese motor aanskaf, sal daar geen sigbare positiewe effek wees op die omgewing of aan enige iemand nie. Dit is gevolglik sinneloos vir hom of haar om minder te ry met sy/haar motor wat baie brandstof verbruik. Dieselfde argument kan gevoer word tydens die koop van konflik-diamante of 'n selfoon wat Kobalt bevat wat onder onmenslike omstandighede gemyn is. Die feit dat hy of sy nie die diamant koop of die foon gebruik nie, gaan geen verskil aan die oorsprong van die diamante of Kobalt maak nie (Kvalnes, 2019:124). 
Die normaliteitsbeginsel is ' $n$ tegniek wat gebruik word om gevoelens teenoor onaanvaarbare gedrag te desensiteer en onetiese gedrag as aanvaarbaar voor te hou. Tipies word die gedrag dus as "normale" gedrag voorgehou want "almal doen dit", of "dit is hoe dit werk in hierdie onderneming". In die gesaghebbende navorsing van Vaughn (1980) word die normalisering van etiese besigheidsgedrag beskryf as gedrag in die organisasie wat so algemeen geword het dat almal dit net so aanvaar ten spyte van die feit dat dit die reëls en veiligheidsgrense ver oorskry. Maatskappywaardes en -grense word dus geskuif en kort voor lank word onaanvaarbare gedrag as aanvaarbaar geag nieteenstaande die feit dat dit steeds onaanvaarbaar is. Die geval van die Challenger-ruimtetuig wat tragies ontplof het op 28 Januarie 1986 dien as voorbeeld van onaanvaarbare gedrag wat genormaliseer is. NASA was deeglik bewus van die seëlringe wat kraak, maar in stede daarvan om die regte ding te doen en die ringe te vervang, het dit normale praktyk geword om dit bloot te seël met stopverf. Trouens, NASA het selfs 'n kontrakteur aangestel om 'n stopverf te ontwerp wat beter sou werk! (Vaughn, 1986, soos aangehaal in The Growth Nation, 2021).

Ten slotte noem Neale en Fullerton (2010) twyfelagtige aksies wat deur verbruikers as eties of oneties geag word, gebaseer op drie kriteria, naamlik 1) het die verbruiker aktief 'n voordeel met sy aksie probeer bewerkstellig, 2) was die aksie wettig al dan nie, en 3) het die besigheid waar die verbruikersaksie plaasgevind het, skade gely al dan nie?

\section{Die rol van demografiese veranderlikes in verbruikersetiek}

Die rol van demografiese veranderlikes is ' $n$ gewilde navorsingsonderwerp en verskeie studies het al gepoog om verwantskappe tussen die demografiese veranderlikes van verbruikers en onetiese gedrag te identifiseer (Chatzidakis \& Maclaran, 2020). Ouderdom is een van die gewildste veranderlikes, en die meeste studies het getoon dat etiese gedrag verbeter namate verbruikers ouer word (Rawwas \& Singhapakdi, 1998; Fullerton et al., 1996; Chatzidakis \& Maclaran, 2020). Interessant genoeg bevind Accenture egter dat meer as ses uit tien jong verbruikers (onder die ouderdom van 30 jaar) handelaars se etiese waardes en opregtheid in ag neem voordat hulle besluit om die produk aan te koop (Schaverien, 2018).

Betreffende die veranderlike geslag, het 'n studie deur die navorsers Fullerton et al. (1996) bevind dat vrouens meer eties georiënteerd is as mans, en dat die verskil in siening van mans veral betekenisvol is indien die slagoffer van sodanige gedrag finansieel aan die kortste end trek. Bossuyt en Van Kenhove (2018:727) verskil egter lynreg met hierdie bevinding. Hul navorsingsbevindinge toon dat vrouens minder eties optree; dit gebeur spesifiek wanneer vrouens verkeerde kleingeld ontvang of foutiewelik gefaktureer word. Die navorsers wys egter daarop dat hierdie gedrag nie aan die finansiële voordeel in hul guns toegeskryf word nie, maar eerder daaraan dat vrouens minder geneig is om in gesprek te tree met die kassier. Hulle is selfs minder geneig om in gesprek te tree indien die fout nie in hul guns is nie. Nog 'n interessante bevinding deur hierdie navorsers is dat hulle 'n sterk positiewe korrelasie geïdentifiseer het tussen die vlak van opvoeding en etiese verbruikersgedrag. Beter gekwalifiseerde verbruikers staan meer krities teenoor twyfelagtige gedrag (Fisher et al., 2002:1024). Daar was egter slegs 'n merkbare positiewe korrelasie tussen die inkomstevlak en etiese verbruikersgedrag. Betreffende geslag en ouderdom word ouer vrouens as beter ingeligte verbruikers beskou (Niinimaki, 2017). Meer gegoede verbruikers toon ook 'n meer kritiese houding teenoor twyfelagtige gedrag, en veral vroue wat welaf is, is meer krities teenoor twyfelagtige etiese gedrag (Bossuyt \& Van Kenhove, 2018:729). Die meerderheid studies toon egter wel dat daar konsensus is dat betekenisvolle verwantskappe bestaan tussen demografiese 
veranderlikes en etiese verbruikersgedrag. Veral die veranderlikes ouderdom en geslag figureer sterk. Helaas is dit ook so dat minder navorsers op veranderlikes soos kwalifikasies, inkomstevlakke, huwelikstatus en werksomstandighede fokus.

\section{Probleemstelling}

Onetiese gedrag hoef egter nie noodwendig onwettig te wees om kritiek uit te lok nie (Neale $\&$ Fullerton, 2010:1). So het brandstofpryse byvoorbeeld vir drie weke tot $\$ 5$ per gallon gestyg in die deelstaat Texas na Orkaan Harvey in 2017 toegeslaan het. Die tekort aan brandstof is blameer vir hierdie prysverhoging (Kumar \& George, 2017). In Nieu-Seeland het lugdienste die prys van interne kaartjies skerp verhoog (Air New Zealand, 2019) tydens die ergste vloede in 20 jaar (NZ Herald, 2019) na aanleiding van 'n skerp styging in vraag na binnelandse vlugte. Toeriste was gestrand in die suide van die Suid-eiland nadat beide brûe na die noorde van die Suid-eiland verspoel het (Bisschoff, 2020). Was dit die etiese besluit om die gestrande toeriste in nood, hoër pryse te vra omdat die ekonomiese wet van vraag en aanbod dit regverdig?

Die aard van etiek is om reg op te tree; dit gaan nie daaroor om slegs binne die riglyne van die wet op te tree nie (Di Meglio, 2020), en daarom kan wettige optrede as oneties beskou word. Dit is egter belangrik om kennis te neem dat besigheidsbestuurders hierdie besluite namens die besighede maak. Juis dit laat Bernstein (1985:24) meer as 30 jaar gelede al die vraag vra hoe hierdie bestuurders self optree as verbruikers in die etiese milieu? Hierdie vraag noop Al-Khatib et al. (1997:750) (soos aangehaal deur Neale en Fullerton, 2008) dat daar 'n besliste behoefte is om verbruikersetiek na te vors om sodoende bestuurders as verbruikers se etiese besluitneming beter te verstaan. Watter verbruikersgedrag is aanvaarbaar, en watter gedrag is nie aanvaarbaar nie? Wat is reg en wat is verkeerd (Barlow, 2007:58), en hoe maak bestuurders hierdie besluite as verbruikers in hul persoonlike lewe (Di Meglio, 2020)? Hierdie studie analiseer gevolglik die etiese gedrag van die bestuurder as 'n verbruiker.

\section{Doelwitte}

Die primêre doelwit is om die etiese gedrag van Suid-Afrikaanse besigheidsbestuurders te ontleed. Die sekondêre doelwitte is gevolglik om:

1. Die etiese gedrag van die besigheidsbestuurders met hul etiese houdings te vergelyk.

2. Onderliggende veranderlikes in die etiese gedrag te identifiseer.

3. Korrelasies te identifiseer tussen etiese gedrag en gekose demografiese veranderlikes.

\section{Etiese klaring}

Die etieknavorsingsprojek is voorgehou en formeel goedgekeur deur die Etiekkomitee van die Fakulteit Ekonomiese en Bestuurswetenskappe (FEMS) aan die Noordwes-Universiteit en die etieksertifikaat (NWU-00337-18-A4) is uitgereik. Die projek is gemagtig om aspekte rakende verbruikersetiek, besigheidsetiek en sportetiek na te vors. Die sertifikaat is geldig tot 31 Desember 2024, waarna daar op daardie stadium aansoek gedoen kan word vir hernuwing.

\section{Navorsingsmetodologie}

Etiese gedrag is moeilik om te bepaal aangesien die verbruiker selde indien ooit sal erken dat hy of sy oneties optree (Fullerton \& Neale, 2010). Andersyds mag die verbruiker probeer om sy of haar onetiese gedrag deur morele neutralisasie of normalisasie as gering af te maak 
(Kvalnes, 2019:2). Juis daarom is dit gebruiklik in die navorsingsmetodologie om na etiekgedrag in die tweede persoon te verwys tydens die ondersoek. So word ten opsigte van twyfelagtige gedrag byvoorbeeld verwys na 'n kollega of 'n kennis wat te veel kleingeld in sy sak steek, eerder as die respondent self (Bisschoff \& Fullerton, 2014:19).

\section{Populasie en steekproef}

Die populasie van die studie bestaan uit besigheidsbestuurders wat oor ten minste drie jaar bestuurservaring beskik en gegradueerd is. (Hierdie artikel rapporteer oor die verbruiker se etiese houdings en gedrag, maar die groter navorsingsprojek sluit ook besigheidsetiek en bestuurdersgedrag in waarin die vereistes gepas is.) 'n Sneeubal-steekproefneming is gebruik, en as wegspringplek vir die sneeubal is die jaarlikse Meestersgraad in Besigheidsadministrasie se studieskool van die Noordwes-Universiteit gebruik. Bestuurslui wat ook vir die besigheidskool se Gevorderde Bestuursprogram en die Middelbestuursprogram ingeskryf was, het ook gekwalifiseer om deel te neem aan die studie. Almal studeer deeltyds, en moet oor 'n graad en ten minste drie jaar bestuurservaring beskik om gekeur te word vir toelating tot die program. Gevolglik bestaan die populasie dus uit gesoute bestuurders wat goed toegerus is om berekende oordele te maak betreffende die besigheidsbesluite wat geneem word (Bisschoff, 2020:5).

Die internetskakel van die vraelys is tydens 'n kort inligtingsessie oor die navorsingsprojek aan die studieskoolgangers, en in die klas tydens die ander programme, voorsien met die versoek dat hulle ook die skakel aan al hul eweknieë in die bedryf sal versprei. Die internetskakel het ' $n$ toestemmingsbrief met kwalifiserende vrae (graad en drie jaar bestuurservaring) vervat, en is op die elektroniese platform Google Forms versprei. Sodra 'n respondent die vraelys voltooi het, is dit outomaties en anoniem in die databasis gestoor. $\mathrm{Na}$ die keerdatum het die navorser die datastel afgelaai en gestuur vir verwerking na die Statistiese Konsultasiediens aan die Noordwes-Universiteit wat die ontledings met die statistiese program IBMSPSS 26 gedoen het. 'n Totaal van 102 respondente se vraelyste kon suksesvol verwerk word.

\section{Vraelys}

Die vraelys wat gebruik is, is oorspronklik ontwerp deur Fullerton (1993:317-323). Hierdie vraelys bestaan uit drie afdelings:

- Afdeling A bestaan uit demografiese inligting (ter wille van die etiese klaring is hierdie vrae beperk tot slegs vier vrae wat moontlik 'n invloed op die etiese houdings en gedrag van respondente kan hê).

- Afdeling B meet respondente se persepsies oor verbruikers se houdings en gedrag deur eties bevraagtekenbare verbruikersgedrag scenario's daar te stel; en

- Afdeling $\mathrm{C}$ meet respondente se persepsies oor bestuurders se gedrag deur eties bevraagtekenbare besigheidscenario's daar te stel.

Hierdie studie handel oor die bestuurder as verbruiker se etiese houding en gedrag, en rapporteer dus oor Afdeling A en B van die vraelys. Die vraelys maak gebruik van 'n gebalanseerde sespunt-rangordeskaal wat strek van 1 (nie aanvaarbaar nie) tot 6 (baie aanvaarbaar). Dit beteken dus dat 'n waarde onder die 3.5-middelpunt toon dat die scenario nie deur die respondent as aanvaarbaar geag word nie, en dus 'n beter etiese houding (of gedrag) aandui, terwyl 'n hoë waarde 'n minder etiese geneigdheid by die respondent sal aandui. 
Die vraelys het die toets van tyd deurstaan en is in verskeie lande en populasies getoets en gevalideer. Fullerton (1993) valideer aanvanklik die vraelys in 1993 in Amerika. In 2008 rapporteer Fullerton, Bisschoff en Moore (2008:3) dat die vraelys suksesvol Suid-Afrikaanse en Sjinese bestuurders se etiese gedrag vergelyk het, terwyl Fullerton en Neale in dieselfde jaar Amerikaanse verbruikersetiek en besigheidsetiek ondersoek het deur die vraelys in te span (Neale \& Fullerton, 2008:7, Fullerton \& Neale, 2010:115). Die vraelys word suksesvol verder deur Fullerton en Neale (2008:3) gebruik om verbruikers- en besigheidsetiek te vergelyk in vyf Engelssprekende lande, naamlik Australië, Nieu-Seeland, Kanada, Suid-Afrika en Amerika. In Suid-Afrika gebruik Craven en Bisschoff (2011), en Rapule (2011) die vraelys in hulle etiekstudies, waarna Bisschoff en Lotriet (2012:10745-7) die vraelys formeel valideer vir gebruik in Suid-Afrika. Sodoende slaag Fullerton en sy medenavorsers daarin om die vraelys te valideer en geskik te bewys vir etiekstudies regoor die wêreld. Hierdie vraelys is met minimale aanpassings in verskeie internasionale etiekstudies op ses kontinente, en in baie verskillende lande (Fullerton \& Bisschoff, 2014:5; Bisschoff, 2018) gebruik om beide verbruikers- en bestuursetiese houdings en gedrag te meet. Die 14 afsonderlike scenario's van Fullerton (1993) wat verbruikersetiek en ook verbruikersgedrag meet deur van scenario's gebruik te maak, is ook geldig om in Suid-Afrika te gebruik (Bisschoff \& Lotriet, 2012:107457, Bisschoff, 2020).

\section{Statistiese tegnieke gebruik}

Beide die demografiese en etiese profiele maak gebruik van beskrywende statistiek. Frekwensieontledings stel die demografiese veranderlikes voor terwyl elke scenario se gemiddelde waarde en standaardafwyking bereken is. Die gemiddeldes is bereken vir beide etiese houdings en etiese gedrag. Die statisties betekenisvolle verskille tussen die houdings en gedrag is bepaal deur die tweestertige t-toets op die $99 \%, 95 \%$ en $90 \%$ vertrouensintervalle. Die praktiese betekenisvolheid van verskille is bepaal deur gebruik te maak van Cohen se effekgrootte (Cohen, 1993:155) en soos verder verfyn deur Ellis en Steyn (2003:52). Die d-waarde is 'n waarde tussen 0 en 1, en word vertolk soos volg: 'n groot praktiese betekenisvolheid bestaan met 'n $d$-waarde van 0.8 en hoër. 'n Medium praktiese betekenisvolheid bestaan by $d$-waardes tussen 0.5 en 0.8 , terwyl 'n $d$-waarde van ten minste 0.2 maar minder as 0.5 'n klein effek uitbeeld (Ellis \& Steyn, 2003:54; Cohen, 1993:155). Hierdie studie ag d-waardes van 0.5 en hoër as aanduidend van medium of hoë vlakke van praktiese betekenisvolheid tussen die etiese houdings en gedrag ten opsigte van 'n scenario.

Die steekproef se geskiktheid word bepaal met Kaiser, Meyer en Olkin se toets (minimum waarde: $\mathrm{KMO} \leq 0.70$ ); die sferisiteit van die data word gemeet deur Bartlett se toets (betekenisvol by $\mathrm{p} \leq 0.05$ ), en die betroubaarheid van die data gebruik die betroubaarheidskoëffisiënt Cronbach alfa (minimum vereiste: $\alpha \leq 0.70$ ) (Field, 2013:668). Die studie gebruik ook eksploratiewe faktorontleding om die latente veranderlikes in die data te identifiseer en daarna Pearsonkorrelasies om verbandskappe vas te stel (waar: $r \leq 0.3$ (swak), $0.3 \leq r \leq 0.5$ (medium) en $r \geq 0.5$ (sterk) korrelasies daarstel) (Pallant, 2010).

\section{Bespreking van die resultate}

\section{Interpretasie van resultate}

Die gebalanseerde ses-punt skaal se middelpunt is 3.5, en weerspieël 'n neutrale houding of gedrag teenoor die scenario wat beoordeel word. Die respondente dui aan in watter mate hulle 
die scenario aanvaarbaar vind, dus dui 'n telling hoër as 3.5 daarop dat respondente die scenario ag as "aanvaarbare gedrag" (Fullerton, 1993:319; Fullerton \& Neale, 2010:116). Gevolglik dui die gemiddelde tellings wat hoër as die neutrale punt is 'n swakker etiese siening of houding van die respondent aan. Hoër tellings is dus onwenslik. Net so is die omgekeerde waar, en in hierdie geval dui lae tellings dan op 'n hoë etiese siening of houding van die bestuurder, wat wenslik is (Bisschoff, 2020).

\section{Demografiese profiel}

Die demografiese profiel toon dat die meerderheid mans (63.4\%) deelgeneem het aan die studie. Die ouderdom van die respondente is gelykmatig versprei oor drie kategorieë, en gesamentlik is $70.3 \%$ tussen 26 en 45 jaar oud. Die meerderheid het meer as 10 jaar werkservaring (47.1\%), waarvan slegs $15.1 \%$ van hulle meer as 10 jaar bestuurservaring het. Die meerderheid het drie tot 10 jaar bestuurservaring (50.0\%). Tabel 1 toon die demografiese profiel van die respondente.

TABEL 1: Demografiese profiel

\begin{tabular}{|l|l|c|}
\hline & \multicolumn{1}{|c|}{ Kategorie } & $\%$ \\
\hline Geslag & Manlik & $63.4 \%$ \\
& Vroulik & $36.6 \%$ \\
\hline Ouderdom (jare) & Jonger as 23 & $7.9 \%$ \\
& $23-25$ & $6.9 \%$ \\
& $26-30$ & $28.7 \%$ \\
& $31-35$ & $20.8 \%$ \\
& $41-45$ & $20.8 \%$ \\
& $46-50$ & $7.9 \%$ \\
& Ouer as 50 & $7.0 \%$ \\
\hline Jare werkservaring & Minder as 3 jaar & $2.9 \%$ \\
& $3-5$ jaar & $22.5 \%$ \\
& $6-10$ jaar & $27.5 \%$ \\
& Meer as 10 jaar & $47.1 \%$ \\
\hline \multirow{5}{*}{ Jare bestuurservaring } & Minder as 3 jaar & $41.4 \%$ \\
& $3-5$ jaar & $25.3 \%$ \\
& $6-10$ jaar & $18.2 \%$ \\
& Meer as 10 jaar & $15.1 \%$ \\
\hline
\end{tabular}

$$
n=102
$$

'n Statistiese korrelasietoets (Pearson) het getoon dat daar geen betekenisvolle sterk verwantskappe $(r \geq 0.30 ; p \leq 0.05,0.10)$ is tussen die demografiese veranderlikes en die etiese gedragscenario's (Sien Bylaag 1) teen die $90 \%$ of die $95 \%$ vertrouensinterval nie. 
Die verskillende scenario's en die respektiewelike gemiddelde waardes word in Tabel 2 voorgehou (Bylaag 1 bevat die volledige beskrywings van die scenario's). Tabel 2 toon ook die betekenisvolle statistiese en praktiese verskille aan tussen die etiese houdings van die respondente en hul siening van etiese gedrag van kollegas en vriende. (Die betekenisvolle verskille word in skuinsdruk in die tabel aangedui.)

TABEL 2: Statistiese en praktiese betekenisvolle verskille tussen etiese houdings en gedrag

\begin{tabular}{|c|c|c|c|c|c|c|}
\hline & \multicolumn{2}{|c|}{ Etiese houding } & \multicolumn{2}{|c|}{ Etiese gedrag } & \multirow{2}{*}{$\begin{array}{c}\text { Effek } \\
\text { grootte (d) }\end{array}$} & \multirow{2}{*}{$\begin{array}{l}\text { t-toets } \\
\text { (p) }\end{array}$} \\
\hline Scenario & Gemiddeld & $\begin{array}{c}\text { Standaard } \\
\text { afwyking }\end{array}$ & Gemiddeld & $\begin{array}{c}\begin{array}{c}\text { Standaard } \\
\text { afwyking }\end{array} \\
\end{array}$ & & \\
\hline $\begin{array}{l}\text { A1: } \begin{array}{l}\text { Hou te veel kleingeld as die } \\
\text { kassier 'n fout maak }\end{array}\end{array}$ & 1.58 & 1.07 & 2.51 & 1.61 & $0.58+$ & $0.00 *$ \\
\hline $\begin{array}{ll}\text { A2: } & \text { Dien vals of vergrote ver- } \\
& \text { sekeringseis in }\end{array}$ & 1.56 & 1.16 & 2.24 & 1.57 & 0.43 & $0.00 *$ \\
\hline $\begin{array}{ll}\text { A3: } & \text { Jok oor jou eie ouderdom } \\
& \text { om afslag te kry }\end{array}$ & 1.72 & 1.31 & 2.30 & 1.61 & 0.36 & $0.00 *$ \\
\hline $\begin{array}{ll}\text { A4: } & \text { Jok oor kinders se ouderdom } \\
& \text { om afslag te kry }\end{array}$ & 1.86 & 1.36 & 2.62 & 1.61 & 0.47 & $0.00 *$ \\
\hline $\begin{array}{ll}\text { A5: } & \text { Koop items wat foutiewelik } \\
\text { geprys is }\end{array}$ & 3.33 & 1.73 & 3.62 & 1.63 & 0.17 & $0.09 * *$ \\
\hline $\begin{array}{ll}\text { A6: } & \text { Samel inligting in maar gaan } \\
& \text { koop dan die produk goed- } \\
& \text { koper elders }\end{array}$ & 4.75 & 1.44 & 4.62 & 1.52 & 0.08 & 0.43 \\
\hline $\begin{array}{ll}\text { A7: } & \text { Herbesoek winkel herhaal- } \\
& \text { delik om van 'n beperkte } \\
& \text { aanbod gebruik te maak }\end{array}$ & 3.42 & 1.56 & 3.77 & 1.61 & 0.22 & $0.06^{* *}$ \\
\hline $\begin{array}{ll}\text { A8: } & \begin{array}{l}\text { Oortree reiskaartjiereëls } \\
\text { doelbewus tot eie voordeel }\end{array}\end{array}$ & 2.55 & 1.56 & 3.09 & 1.68 & 0.32 & $0.01 *$ \\
\hline $\begin{array}{ll}\text { A9: } & \text { Poog om produk om te ruil } \\
\text { teen die reëls }\end{array}$ & 2.34 & 1.70 & 2.71 & 1.78 & 0.17 & $0.10 * *$ \\
\hline $\begin{array}{ll}\text { A10: } & \text { Skep vals verwysingsprys } \\
& \text { om produkprys in winkel af } \\
& \text { te stry }\end{array}$ & 3.21 & 1.73 & 3.22 & 1.64 & 0.01 & 1.10 \\
\hline 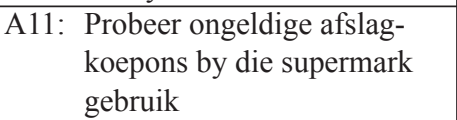 & 1.96 & 1.43 & 2.47 & 1.64 & 0.31 & $0.01 * *$ \\
\hline 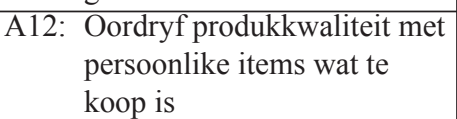 & 2.25 & 1.45 & 2.77 & 1.67 & 0.31 & $0.01 * *$ \\
\hline $\begin{array}{l}\text { A13: Oneerlik in navorsingsop- } \\
\text { names }\end{array}$ & 2.16 & 1.36 & 2.78 & 1.58 & 0.39 & $0.01 * *$ \\
\hline $\begin{aligned} \text { A14: } & \text { Neem klere op sig, dra dit, } \\
& \text { en gee dit terug volgende dag }\end{aligned}$ & 1.90 & 1.41 & 2.48 & 1.79 & 0.33 & $0.01 * *$ \\
\hline Individuele gemiddeld & 2.47 & 1.45 & 2.94 & 1.65 & & \\
\hline
\end{tabular}

Praktiese betekenisvolheid: ${ }^{+} \mathrm{d} \geq 0.8$ (groot effek); en ${ }^{++} 0.5 \leq \mathrm{d}<0.8$ (medium effek) Statistiese betekenisvolheid: * $\mathrm{p} \leq 0.01 ; * * \mathrm{p} \leq 0.05$; en $* * * \mathrm{p} \leq 0.10$ 
Die meerderheid van die scenario's dui op aanvaarbare etiese houdings en gedrag omdat hulle gemiddelde waardes onder 3.5 is. Slegs scenario A6: Samel inligting in maar koop die produk elders goedkoper word as onaanvaarbaar geag. 'n Tipiese praktiese manifestasie van hierdie scenario is wanneer 'n respondent byvoorbeeld na golfstokke gaan kyk, dit slaan, en selfs die verkoopspersoneel in die golfwinkel raadpleeg, maar daarna die gekose golfstokke aanlyn bestel. Beide die houding hieroor (4.75) en die gedrag (4.62) toon dat respondente dit aanvaarbaar vind (en gevolglik met tellings bo die middelpunt van 3.5, oneties handel). Die meeste scenario's het ook standaardafwykings wat neig na 'n waarde van 1.5 of hoër. Dit beteken dat die respondente nie dieselfde menings huldig nie en van mekaar verskil in hul siening van beide die houdings en gedrag van die scenario's.

Die respondente is onseker aangaande scenario's A5: Foutiewelik geprysde produkte en A7: Herhaaldelike besoeke om gebruik te maak van beperkte aanbieding per kliënt; beide scenario's se houding- en gedragstellings is naby die middelpunt van 3.5. Figuur 1 toon die individuele tellings per scenario en vergelyk die houding- en gedragswaardes. Die middelpuntwaarde word ook aangedui in die figuur asook as die aanvaarbare $(<3.5)$ en onaanvaarbare (>3.5) etiese houdings- en gedragsareas.

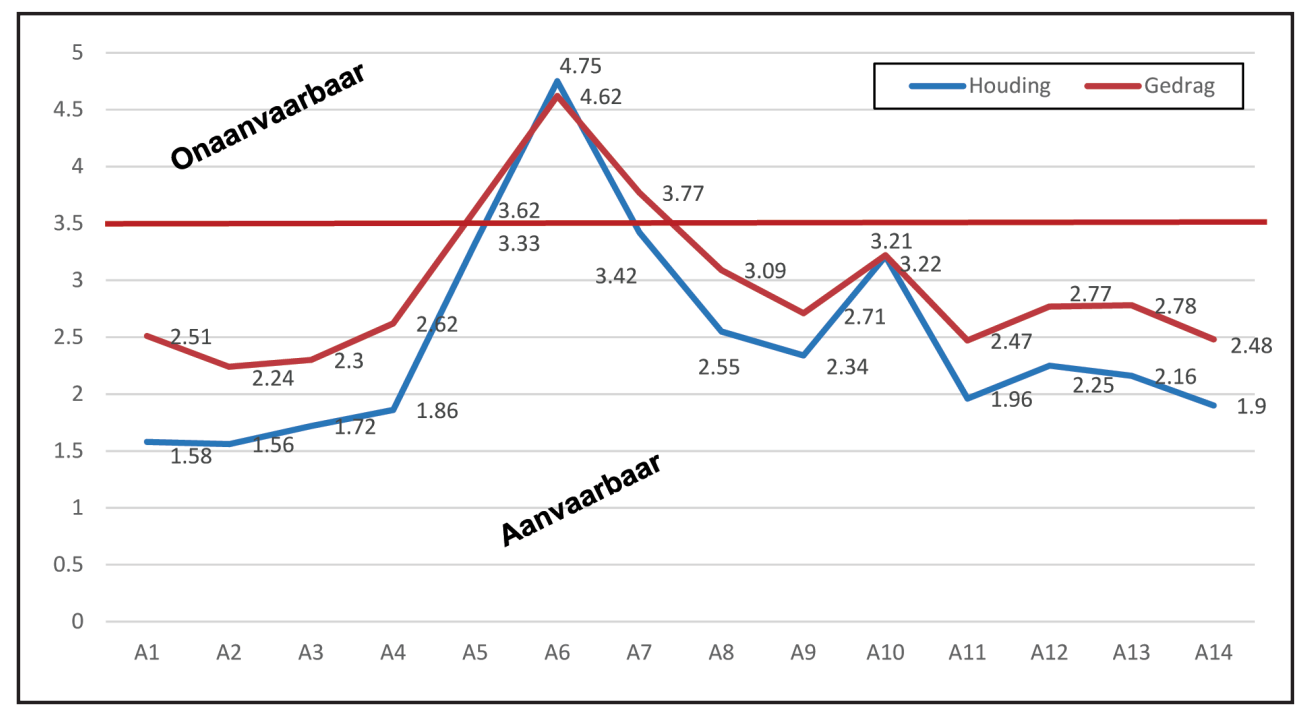

Figuur 1: Gemiddelde waardes van die etiese houdings en gedrag van respondente

Die twee-stert t-toets (sien Tabel 2) toon dat daar statisties betekenisvolle verskille is tussen die etiese houdings en gedrag wat die respondente waarneem. Vyf van die scenario's toon statistiese betekenisvolle verskille aan op die $99 \%$ vertrouensinterval $(\mathrm{p} \leq 0.01)$, terwyl nog een statisties betekenisvol verskil op die $95 \%$ vertrouensinterval $(\mathrm{p} \leq 0.05)$. Voorts verskil nog drie scenario's betekenisvol op die $90 \%$ vertrouensinterval $(\mathrm{p} \leq 0.10)$. Dit beteken dat nege van die 14 scenario's statistiese verskille aantoon tussen etiese houdings en gedrag van die respondente. Nadere inspeksie van die gemiddelde waardes toon verder dat die scenario's se houdingswaardes almal laer is as die gedragswaardes; dit toon aan dat die gedrag meer aanvaarbaar geag word as die houding ten opsigte van die scenario (dit dui gevolglik dat onaanvaarbare etiese gedrag as aanvaarbaar beskou word). Die gevolgtrekking is nieteenstaande 
die feit dat die respondente bewus is van wat aanvaarbare gedrag is al dan nie, hulle voel dat hul vriende en kollegas wel gedrag openbaar wat onaanvaarbaar is. Onetiese gedrag is gevolglik aan die orde van die dag met die meerderheid scenario's (nieteenstaande die feit dat hulle besef dit is oneties om so op te tree). Die gemiddelde waarde van die 14 scenario's ondersteun die siening waar houding 'n waarde van 2.47 het teenoor die gemiddelde 2.94 waarde van gedrag. Dit is egter opmerklik dat beide waardes onder die middelpunt van 3.5 is (wat aanvaarbare etiese houdings of gedrag weerspieël).

Dit is egter insiggewend dat die effekgrootte as sekondêre toets vir prakties betekenisvolle verskille slegs een praktiese betekenisvolle verskil tussen die houding en gedrag van die respondente aantoon. 'n Medium effek van 0.58 word aangedui by scenario A1: Hou te veel kleingeld. Al die ander scenario's toon slegs klein (en dus ignoreerbare) praktiese betekenisvolle verskille aan. Daar is dus in die geheel statisties betekenisvolle verskille, maar nie prakties betekenisvolle verskille nie.

\section{Faktore van etiese gedrag}

Die gedrag van die respondente is verder ontleed om te bepaal of daar nie gemeenskaplike onderliggende faktore bestaan nie. Die eksploratiewe faktorontledingstegniek is ingespan om hierdie latente veranderlikes uit te lig. Die Varimax rotasie-konfigurasie is gekies omdat die spesifieke rotasie besonder geskik is om die maksimum variansie te verklaar (Field, 2013). 'n Geldige faktorontleding is egter afhanklik van geskikte data, en word daar eerstens genoegsame datapunte (of steekproef genoegsaamheid) vereis; tweedens, dat die data wat ingesamel is, betroubaar is; en derdens, dat daar nie ongelyke of kombinasies variansie in die data bestaan nie. Die resultate van hierdie toetse word respektiewelik deur die Kaiser, Meyer en Olkin toets vir geskiktheid van die steekproef, die Cronbach alfa-koëffisiënt en die Bartlett-toets vir sferisiteit bepaal. Die resultate van hierdie toetse om die geskiktheid van die datastel te bepaal, word in Tabel 3 voorgehou.

TABEL 3: Kaiser, Meyer en Olkin, Cronbach alfa en Bartlett se toetse

\begin{tabular}{|l|l|c|}
\hline \multicolumn{2}{|l|}{ Kaiser, Meyer en Olkin se toets vir steekproef geskiktheid } & $\mathbf{0 . 7 9 0}$ \\
\hline Bartlett se toets van sferisiteit & Chi-kwadraat & 396.550 \\
& Grade van vryheid & 91 \\
& Betekenisvolheid $(\mathrm{p} \leq 0.05)$ & 0.00 \\
\hline Cronbach alfa & Alfa-koëffisiënt $(\alpha)$ & $\mathbf{0 . 8 5 3}$ \\
& Aantal items & $\mathbf{1 4}$ \\
\hline
\end{tabular}

Tabel 3 toon dat die vereiste minimum waarde van steekproef genoegsaamheid $(0.70)$ gerieflik behaal is $(\alpha=0.790)$ en dat daar genoegsame datapunte is. Die tabel toon ook dat daar nie probleme is betreffende interne variansie of kombinasies daarvan nie, aangesien die Bartletttoets betekenisvol is $(\chi 2(91)=396.550, p<0.05)$ (Laerd Statistics, 2020). Die Cronbach alfa-koëffisiënt is 0.853 wat gemaklik die vereiste grens $(\alpha \geq 0.70)$ oorskry. Die data is dus geskik om onderwerp te word aan multivariante ontledings (byvoorbeeld eksploratiewe faktorontleding). Die resultate van die faktorontleding word in Tabel 4 voorgehou. 
TABEL 4: Varimax geroteerde faktorontleding

\begin{tabular}{|l|c|c|c|}
\hline Scenario's & \multicolumn{3}{|c|}{ Faktor } \\
\hline & $\mathbf{1}$ & $\mathbf{2}$ & $\mathbf{3}$ \\
\hline A2: Vals versekeringseis & .862 & & \\
\hline A3: Jok oor eie ouderdom & .748 & & \\
\hline A4: Jok oor kinders se ouderdom & .712 & & \\
\hline A1: Hou verkeerde kleingeld & .697 & & \\
\hline A14: Gee klere terug na dit gedra is & .584 & & \\
\hline A12: Kul die bure & & .772 & \\
\hline A10: Verskaf vals verwysingsprys & & .730 & \\
\hline A13: Oneerlik in navorsing & & .680 & \\
\hline A11: Kul met supermark-koepons & & .635 & \\
\hline A9: Ruil produk om by ander winkel & & .449 & \\
\hline A6: Toets produkte in winkel en bestel elders & & & .773 \\
\hline A5: Swyg oor foutiewe pryse & $\mathbf{3 7 . 0 4 \%}$ & $\mathbf{1 3 . 7 1 \%}$ & $\mathbf{9 . 7 7 \%}$ \\
\hline A7: Misbruik beperkte aanbiedings & $\mathbf{3 7 . 0 4 \%}$ & $\mathbf{5 0 . 7 5 \%}$ & $\mathbf{6 0 . 5 2 \%}$ \\
\hline A8: Oortree reëls op kaartjie & $\mathbf{0 . 8 5}$ & $\mathbf{0 . 7 0}$ \\
\hline Variansie verklaar & & .764 \\
\hline Kumulatiewe variansie verklaar & & .605 \\
\hline Betroubaarheid (Cronbach alfa) & & & .547 \\
\hline Onttrekkingsmetode: Hoofkomponentanalise; Rotasiemetode: Varimax met Kaiser- \\
\hline \multicolumn{1}{|c|}{ normalisering; Rotasie konvergeer in 6 iterasies. } & & \\
\hline
\end{tabular}

Die faktorontleding toon dat daar inderdaad drie latente veranderlikes (genoem faktore) in die data bestaan wat kumulatief $60.52 \%$ van die variansie verklaar. Dit word beskou as 'n goeie passing met die data (die verklaarde variansie oorskry 50\%, maar verkieslik 60\%) (UCLA, 2020). Voorts is die individuele betroubaarheid van al drie die faktore bevredigend ( $\operatorname{met} \alpha=0.82$; 0.85 en 0.70, respektiewelik). Die faktore kan dus met vertroue ingespan word (Field, 2013).

Faktor 1: Misleidende gedrag

Al die stellings in Faktor 1 handel oor misleidende gedrag om persoonlike voordeel te bekom. Die gedrag is dus daarop geskoei om persoonlike voordeel te trek deur misleidende inligting te verskaf of om stil te bly en nie die kassier reg te help dat hy of sy die verkeerde kleingeld gegee het nie. Dit is die belangrikste faktor, want dit verklaar $37.04 \%$ van die variansie. 
Faktor 2: Oneerlike optrede

Die scenario's in die faktor dui op blatante oneerlike optrede. Jok of oordryf ten opsigte van die kwaliteit van die produkte wat verkoop word, verkul winkel deur goedere terug te gee waar dit nie gekoop is nie, jok op navorsingsvraelyste, en gebruik koepons wat nie geldig is. Al hierdie gedrag is gerig en oneerlik ten einde persoonlike voordeel te ontvang. Die faktor verklaar $13.71 \%$ van die variansie.

Faktor 3: Prysvoordeel

Die onderliggende tema in Faktor 3 dui op gedrag om 'n prys-georiënteerde voordeel te bekom. Die produk is goedkoper by 'n ander winkel, afslag, besoek die winkel herhaalde kere om die beperkte aanbod uit te buit, en breek die reëls om afslag vir 'n filmvertoning te kry. Hierdie faktor verklaar $9.77 \%$ van die variansie.

\section{Korrelasies in etiese gedrag}

Die korrelasies tussen die faktore is eerstens ondersoek, waarna daar ondersoek ingestel is na demografiese veranderlikes en faktore. Laastens is individuele scenario's gekorreleer met die demografiese veranderlikes. Tabel 5 toon die korrelasies tussen die drie faktore.

TABEL 5: $\quad$ Korrelasies tussen die drie faktore

\begin{tabular}{|l|l|c|c|c|}
\hline \multicolumn{2}{|c|}{} & $\begin{array}{c}\text { Misleidende } \\
\text { gedrag }\end{array}$ & $\begin{array}{c}\text { Oneerlike } \\
\text { optrede }\end{array}$ & Prysvoordeel \\
\hline \multirow{3}{*}{$\begin{array}{l}\text { Misleidende } \\
\text { gedrag }\end{array}$} & Pearson se korrelasie & 1 & $.561 * *$ &. $\mathbf{4 0 6 * *}$ \\
\cline { 2 - 5 } & Sig. (2-tailed) & & .000 & .000 \\
\cline { 2 - 5 } & $\mathrm{N}$ & & 72 & 84 \\
\hline \multirow{3}{*}{$\begin{array}{l}\text { Oneerlike } \\
\text { optrede }\end{array}$} & Pearson se korrelasie & & 1 &. $\mathbf{4 5 6 * *}$ \\
\cline { 2 - 5 } & Sig. (2-tailed) & & & .000 \\
\cline { 2 - 5 } & $\mathrm{N}$ & & & 71 \\
\hline \multicolumn{2}{|l|}{$* *$. Korrelasie is beduidend op die 0.01-vlak (2-stertig). } \\
\hline
\end{tabular}

Daar is medium positiewe en betekenisvolle korrelasies $(\mathrm{r}=0.561, \mathrm{r}=0.406, \mathrm{r}=0.456 ; \mathrm{p} \leq 0.01)$ op die $99 \%$ vertrouensinterval tussen die drie faktore. Hierdie bevinding beteken dat die faktore mekaar wel beïnvloed. Sou daar dus 'n suksesvolle intervensie aangebring word om die gedrag van enige van die drie faktore te verbeter, sal daar dus 'n matige verbetering terselfdertyd teweeg gebring word in die ander faktore, al was die ander twee faktore nie direk deur so 'n intervensie geteiken nie. Die feit dat die korrelasies nie oormatig sterk is nie, was te wagte aangesien oormatige sterk korrelasies dui op 'n gesamentlike faktor eerder as twee afsonderlike faktore.

Die demografiese veranderlikes dui slegs twee swak positiewe korrelasies aan met die faktore wat betekenisvol is. Hier toon werkservaring swak positiewe korrelasies met die faktore 
misleidende gedrag $(\mathrm{r}=0.227 ; \mathrm{p} \leq 0.05)$ en oneerlike optrede $(\mathrm{r}=0.250 ; \mathrm{p} \leq 0.05)$. Soortgelyke korrelasies bestaan tussen die demografiese veranderlikes en enkele van die individuele scenario's. Ouderdom korreleer betekenisvol maar swak positief met A1: Hou ekstra kleingeld $(\mathrm{r}=0.216 ; \mathrm{p} \leq 0.05)$ en A6: Vals verwysingspryse $(\mathrm{r}=0.267 ; \mathrm{p} \leq 0.10)$, maar swak negatief met A6: Samel inligting in maar koop produk elders $(\mathrm{r}=0.218 ; \mathrm{p} \leq 0.05)$. Werkservaring korreleer of betekenisvol positief (maar swak) met A1: Hou ekstra kleingeld $(\mathrm{r}=0.290 ; \mathrm{p} \leq 0.10)$, A3: Jok oor ouderdom ( $\mathrm{r}=0.290 ; \mathrm{p} \leq 0.05)$, A11: Ongeldige koepons $(\mathrm{r}=0.257 ; \mathrm{p} \leq 0.10)$, en A13: Oneerlik in navorsing ( $\mathrm{r}=0.295 ; \mathrm{p} \leq 0.05)$. A3: Jok oor ouderdom (A3) is die enigste swak positiewe korrelasie wat betekenisvol is met die demografiese veranderlike Bestuursondervinding $(\mathrm{r}=0.271 ; \mathrm{p} \leq 0.10)$.

Die korrelasies toon dat daar wel verwantskappe bestaan tussen die demografiese profiel van die respondente en die scenario's. Hierdie verwantskappe is egter swak en te laag om spesifieke intervensies direk daaraan te koppel; die sukses van sulke pogings om etiese gedrag te verbeter sal minimaal wees. Dit sal dus beter wees om die faktore direk aan te spreek eerder as om demografiese ingrepe aan te wend.

\section{Opsomming}

Die primêre doelstelling van hierdie studie was om te bepaal of bestuurders se etiese houdings verskil van hul optrede. Weet hulle dat hulle oneties optree, of doen hulle dit bloot uit onkunde indien hul wel onetiese verbruikersgedrag openbaar. Die resultate toon duidelik dat die bestuurders se etiese houdings oor verbruikersetiek op 'n beter vlak is as hul gedrag. In die praktyk beteken dit dus dat hulle weet wat die regte verbruikersgedrag is, maar tog afwyk daarvan om persoonlike voordele uit onetiese gedrag te realiseer. Beide die etiese verbruikershoudings- en gedrag is onder die middelpunt; dit dui daarop dat alhoewel die bestuurders wel eties optree, nieteenstaande die feit dat die gedrag se telling (2.94) die telling van die etiese houdings (2.47) oorskry.

Drie onderliggende faktore in etiese gedrag is ook geïdentifiseer, naamlik misleidende gedrag, oneerlike optrede en die bekom van 'n prysvoordeel. Daar is betekenisvolle positiewe verwantskappe tussen hierdie drie faktore. Daar is egter geen betekenisvolle verwantskappe tussen die demografiese veranderlikes en die gedragscenario's nie.

\section{BIBLIOGRAFIE}

Air New Zealand. 2019. Air New Zealand. Book with confidence. https://www.airnewzealand.co.nz/book [15 Desember 2019].

Barlow, RD. 2007. Combating fraud and abuse. Healthcare purchasing news, 31(3):58-62.

Bernstein, P. 1985. Cheating - the new national pass time? Business, 35(4):24-33.

Bisschoff, CA \& Fullerton, S. 2014. Managerial business ethics in South Africa: An exploratory comparison - 1987 and 2009. African Journal of Business Ethics, 5(1):14-25.

Bisschoff, CA \& Lotriet, RA. 2012. Factor identification in managerial ethics. African Journal of Business Ethics, 6(430):10741-10749.

Bisschoff, CA. 2018. 'n Longitudinale ondersoek na verbruikersetiek in Suid-Afrika. Tydskrif vir Geesteswetenskappe, 58(3):530-547, September.

Bisschoff, CA. 2020. 'n Ontleding van Suid-Afrikaanse sakebestuurders se etiese besigheidsbesluitneming: Tendense van 2007 tot 2019. Litnet Akademies (Ekonomiese Wetenskappe), 17(3):123-157.

Bossuyt, S \& Van Kenhove, P. 2018. Assertiveness bias in gender ethics: why women deserve the benefit of the doubt. Journal of Business Ethics, 150:727-739. 
Chatzidakis, A \& Maclaran, P. 2020. Gendering consumer ethics. International Journal of Consumer Studies, https://doi.org/10.1111/ijcs.12567 [12 Junie 2021].

Cohen, J. 1992. A power primer. Psychological Bulletin, 112(1): 155-159, July.

Craven, P \& Bisschoff, CA. 2011. 'n Vergelykende studie van etiese bestuurspersepsies tussen bestuur en die produksie-afdeling in 'n internasionale landboumaatskappy. Tydskrif vir Geesteswetenskappe, 51(3):354:372.

Di Meglio, F. 2020. Ethics in marketing. https://www.monster.com/career-advice/article/ethics-inmarketing [15 Junie 2021]

Ellis, SM \& Steyn, HS. 2003. Practical significance (effect sizes) versus or in combination with statistical significance (p-values). Management dynamics, 12(4):51-53.

Field, A. 2013. Discovering statistics using SPSS. 5th ed. London: Sage.

Fisher, CB, Hoagwood, K, Boyce, C, Duster, T, Frank, DA, Grisso, T \& Levine, RJ. 2002. Research ethics for mental health science involving ethnic minority children and youths. American Psychologist, 57:1024-1040.

Fullerton, S \& Bisschoff, CA. 2013. Ethical predisposition of business students: using the results from 12 countries to compare attitudes on six continents. 7th International Business Conference, Mahe, Seychelles. 2-5 Sep.

Fullerton, S \& Neale, L. 2010. Attitudes towards Consumer Transgressions in the Marketplace. Association of Marketing Theory and Practice Proceedings. https://digitalcommons.georgiasouthern.edu/amtpproceedings_2010/70 [10 Mei 2021].

Fullerton, S. 1993. The ethical predisposition of our next generation of business and community leaders. Proceedings of the Atlantic Marketing Association, 317-323. March.

Fullerton, S, Bisschoff, CA \& Moore, DL. 2008. Examining the ethical predisposition of the next generation of business leaders in China and the Republic of South Africa. South African Journal of Economic and Management Sciences, 11(2):157-171.

Fullerton, S, Kerch, KB \& Dodge, HB. 1996. Consumer ethics: an assessment of individual behaviour in the marketplace. Journal of Business Ethics, 15(7):805-814.

Goodstein, JD \& Wicks, AC. 2007. Corporate and stakeholder responsibility: making business ethics a two-way conversation. Business ethics quarterly, 17(3):375-398.

Grove, SJ, Vitell, SJ \& Strutton, D. 1989. Non-normative consumer behavior and the techniques of neutralization. In Bagozzi, R \& Peter, JP (eds), Proceedings of the 1989 AMA Winter Educators Conference, American Marketing Association, Chicago, IL, pp. 131-5.

Kaptein, M \& van Helvoort, M. 2019. A model of neutralization techniques. Deviant behavior, 40(10):1260-1285.

Kumar, D \& George, L. 2017. Why consumers pay the price for hurricane fuel shortages. https://www. reuters.com/article/us-storm-harveygasoline-storage-analysi/why-consumers-pay-the-price-forhurricane-fuel-shortages-idUSKCN1C10EF [10 Mei 2019].

Kvalnes, Ø. 2019. Moral Neutralization. Champaign, IL: Palgrave Pivot.

Kvalnes, Ø \& Nordal, S. 2018. Normalization of questionable behavior: An ethical root of the financial crisis in Iceland. Journal of Business Ethics, 159(3):1-15.

Leard Statistics. 2020. Sphericity. https://statistics.laerd.com/statistical-guides/sphericity-statistical-guide. php [19 Junie 2021].

Mcquene, A. 2009. NUMSA. Biowatch wins GMO court case. http://www.numsa.org.za/article. php?cat=\&id=1029 [ 23 June 2020].

Neale, L \& Fullerton, S. 2008. Comparing the ethical predisposition of university students in five Englishspeaking countries: An examination of 14 questionable consumer actions. In W Kehoe \& L Whitten (eds). Proceedings of the Society of Marketing Advances, pp. 193-194

Neale, L \& Fullerton, S. 2010. Attitudes towards consumer transgressions in the marketplace. In: Proceedings of Association of Marketing Theory and Practice Conference 2010, 25-27 March 2010, Hilton Head, USA.

Niinimaki, K. 2017. Aesthetical or rational: gender differences in ethical fashion consumption. Journal of Consumer Ethics, 1(2):6-17.

NZ Herald. 2019. Travel chaos in South Island as flights cancelled and roads cut. https://www.nzherald. co.nz/nz/news/article.cfm?c_id=1\&objectid=12291929 [19 February 2020]. 
Ogoun, S \& Odogwu, TKZ. 2020. The adequacy of the Auditor's Report in the Anti-Graft Age: A forensic view. iBusiness, 12(1):1-14.

Pallant, J. 2010. SPSS Survival guide. 6th ed. New York, NY: McGraw Hill Education.

Rapule S. 2011. An evaluation of the ethical behaviour of MBA students at a selected business school. 7th International Business Conference, Mahe, Seychelles. 2-5 Sep.

Rawwas YA \& Singhapakdi, A. 1998. Do consumers' ethical beliefs vary with age? A substantiation of Kohlberg's typology in marketing. Journal of Marketing Theory and Practice, 6(2):26-38.

Schaverien, A. 2018. Consumers do care about retailers' ethics and brand purpose. https://www.forbes. $\mathrm{com} /$ sites/annaschaverien/2018/12/12/consumers-do-care-about-retailers-ethics-and-brand-purposeaccenture-research-finds/?sh=c51 fa8016f21 [19 March 2021].

Smith, A, Hume, EC, Zimmerman, R \& Alan, D. 2007. The global significance of locus of control in ethical decision-making. Journal of College Teaching and Learning, 4(2):7-12.

Sykes, G \& Matza, D. 1957. Neutralization: A theory of delinquency. Chicago, IL: University of Chicago.

The Growth Nation. 2021. Are you normalising bad behaviour? https://thegrowtheq.com/are-younormalizing-bad-behavior/ [14 Mei 2021].

University of California Los Angeles (UCLA). 2020. Statistical consulting: a practical introduction to factor analysis. https://stats.idre.ucla.edu/spss/seminars/introduction-to-factor-analysis/a-practicalintroduction-to-factor-analysis-confirmatory-factor-analysis/ [14 Mei 2021].

Vaughn, D. 1980. The normalization of deviance. Thousand Oaks, CA: Sage 
BYLAAG 1: Verbruiksersgedragscenario's wat etiese aspekte simuleer:

\begin{tabular}{|c|c|}
\hline Scenario & Beskrywing \\
\hline A1 & $\begin{array}{l}\text { 'n Medewerker is te veel kleingeld gegee deur die winkelassistent by die bakkery op } \\
\text { die hoek. U medewerker hou die ekstra kleingeld. }\end{array}$ \\
\hline A2 & $\begin{array}{l}\text { 'n Vriend se woonstel is deur 'n vuur beskadig. Terwyl verliese aan die verse- } \\
\text { keringsmaatskappy gerapporteer word, sluit u vriend items in wat sy nog nooit besit } \\
\text { het nie en vermeerder sy ook die waarde van items wat verloor is in die vuur. }\end{array}$ \\
\hline A3 & $\begin{array}{l}\text { U het gesien hoe ander mense hul eie ouderdom verdraai om voordeel te trek uit afslag } \\
\text { wat aan senior burgers gebied word. }\end{array}$ \\
\hline A4 & $\begin{array}{l}\text { U het gesien hoe ander mense hul kinders se ouderdomme verdraai om sodoende voor- } \\
\text { deel te trek uit afslag vir kinders. }\end{array}$ \\
\hline A5 & $\begin{array}{l}\text { 'n Vriend van } u \text { vind ' } n \text { item in 'n winkel ooglopend verkeerdelik laer geprys is. Eerder } \\
\text { as om die winkel in kennis te stel, koop u vriend die item teen die laer prys aan. }\end{array}$ \\
\hline A6 & $\begin{array}{l}\text { Sommige mense sal na 'n handelaar gaan om inligting oor 'n spesifieke produk te verkry } \\
\text { en maak dan van hierdie inligting gebruik om die produk vanaf 'n goedkoper bron aan } \\
\text { te koop. ('n Katalogus en die Internet is twee voorbeelde.) (Byvoorbeeld om in die } \\
\text { winkel verskoopsadvies in te win en gholfstokke uit te toets, net om die stokke daarna } \\
\text { goedkoper oor die Internet te bestel) }\end{array}$ \\
\hline A7 & $\begin{array}{l}\text { Sommige mense sal herhaaldelik na dieselfde winkel gaan om sodoende voordeel te } \\
\text { trek uit 'n aanbod wat jou beperk ten opsigte van die hoeveelheid wat per besoek } \\
\text { aangekoop word. }\end{array}$ \\
\hline A8 & $\begin{array}{l}\text { Iemand wat jy ken het 'n reiskaartjie aan 'n vriend verkoop ten spyte daarvan dat dit } \\
\text { deur die reiskaartjie se reëls verbied word }\end{array}$ \\
\hline A9 & $\begin{array}{l}\text { Deur hoorsê hoor jy dat 'n buurman 'n produk inruil by 'n winkel anders as die winkel } \\
\text { waar die produk aangekoop is. }\end{array}$ \\
\hline A10 & $\begin{array}{l}\text { Iemand wat jy ken het 'n televisie gaan koop. Om 'n beter transaksie te bewillig, vertel } \\
\text { jou kennis aan die verkoopspersoon dat 'n ander handelaar die televisie teen 'n baie } \\
\text { goedkoper prys verkoop. Die handelaar, sonder om die mededinger se prys te verifieer, } \\
\text { pas sy prys by die laer prys aan. Jou kennis koop die televisie. }\end{array}$ \\
\hline A11 & $\begin{array}{l}\text { By 'n supermark ruil die persoon voor jou koeponne vir items wat nie aangekoop is nie } \\
\text { in. }\end{array}$ \\
\hline A12 & $\begin{array}{l}\text { Om 'n item by 'n garage-verkoping te verkoop, oordryf jou bure die kwaliteit van die } \\
\text { item. }\end{array}$ \\
\hline A13 & Mense wat jy ken is soms oneerlik in bemarkingsnavorsingsopnames. \\
\hline A14 & $\begin{array}{l}\text { Vriende van jou koop klere by 'n plaaslike handelaar aan. Na hulle die klere gedra het, } \\
\text { sien hulle dit by 'n ander winkel teen baie laer pryse. Hulle neem die klere terug, eis ' } \\
\text { terugbetaling, en gaan koop hulle dieselfde klere by die winkel wat die laer prys bied. }\end{array}$ \\
\hline
\end{tabular}

Bron: Fullerton (1993) 